Full Title

\title{
Development of a Professional Competency Framework for UK Food Science Graduates
}

\section{Name(s) of author(s)}

Emma Weston, Tim Foster, Jim Crilly Liz Mossop

\section{Contact information for corresponding author}

Emma JE Weston, Division of Food, Nutrition and Dietetics, School of Biosciences, University of Nottingham, Nottingham, UK. emma.weston@nottingham.ac.uk

ORCID https://orcid.org/0000-0002-2161-4103

Tel: 0044 (0) 1159516214

All other author affiliations [with complete addresses]

Tim Foster, Division of Food, Nutrition and Dietetics, School of Biosciences, University of Nottingham, Nottingham, UK. tim.foster@nottingham.ac.uk ORCID https://orcid.org/0000-0002-9757-9615

Jim F Crilly, Nottingham University Business School, University of Nottingham, Nottingham, UK. elaine.jammali@nottingham.ac.uk

ORCID https://orcid.org/0000-0002-8035-4620

Liz H Mossop, University of Lincoln, Lincoln, Lincolnshire, LN6 7TS, UK. LMossop@lincoln.ac.uk

ORCID https://orcid.org/0000-0003-1317-1856

Word count of text, "7,204 words"

[Include title page, Abstract, Practical Application, body text, and references. Do not include tables or figure captions. There is a 7,500-word limit for Journal of Food Science research papers; 10,000-word limit for Concise Reviews and Hypothesis papers. For reviews with more than 10,000 words, please submit to Comprehensive Reviews in Food Science and Food Safety.]

Short version of title [Under 40 characters, followed by ellipse $(\ldots)$ ]

food graduates competency framework (..)

Choice of journal/section

Journal of Food Science Education section:

- Research in food science education.

Previous address(es)

(If research was conducted at a different affiliation than that listed above) N/A

\section{Author disclosures}

(If applicable or if required by the funding institution) N/A

[END PAGE 1] 
Food science-based graduates are a significant proportion of the UK food and drink industry's workforce. Aside from technical standards, there is no cohesive competency framework to support key stakeholders; employers, students and degree providers. Clarity of desirable competencies for the range of graduate opportunities available would enable students to undertake effective career planning and personal development, and educators to refine programs to satisfy market needs. Using a previously developed language tool, a Likert style, industry-wide online survey in UK and Republic of Ireland (ROI) was conducted involving 218 participants from a broad range of food science-related employment areas, evaluated by a combination of descriptive and multivariate data analysis. The survey outcomes indicate types of desirable competencies in a food science graduate. The tailored competency framework, Competencies for Food Graduate Careers (CFGC), is a set of 48 elements across 8 themes, outlining which are desirable for each of 14 typical initial graduate roles. To enhance the quality of 'oven-ready' graduates entering the food industry, it is recommended CFGC be used for careers education and competency development in higher education. The framework is aimed to have further applications for job specification development and also to improve awareness of careers in the food industry.

5 Keywords: Principal component analysis (PCA), competencies, food science workforce readiness, curriculum, education.

Practical Application: NOTE: Do not include a PA for JFS Concise Reviews, JFSE, and CRFSFS papers. N/A 
62 Ensuring students of vocationally based courses have understanding of and the ability to develop the requirements of graduate employers is a duty of contemporary degree educators. This includes the broader competencies associated with success in the workplace and may vary dependent on role undertaken. Competency frameworks for graduate vocations can be used beyond curriculum development, having the potential to improve a student's awareness of the desirable skills and behaviors for specific career pathways and thus inform choice and plans for personal development.

UK degree subject standards or 'QAA' benchmark statements such as the 'Agriculture, horticulture, forestry, food, nutrition and consumer science' (The Quality Assurance Agency for Higher Education, 2016) provide specific technical skill requirements for course types under broad discipline groups. Food science degrees in the UK demonstrate reference to content of this QAA statement. Aspects of broader competencies that may be required for graduates to possess, are found in the 'generic skills' section, but are unspecific or broadly applicable to the many degree course types covered in the statement. This limits understanding of the type of desirable competencies expected in a food science graduate undertaking their first role, particularly when in reality there are a range of pathways to choose across research, development, manufacturing, retail and compliance. The relatively new UK-based IFST degree accreditation (Institute of Food Science and Technology, n.d.) makes reference to this QAA statement as part of its compliance guidelines for technical and broader competence.

The USA-based IFT standard (Institute of Food Technologists, 2016), appears to be broadly comparable to the QAA statement (2016), but more targeted to food science degree requirements. A number of educators in the USA have published work on compliance of degree curricula to the IFT standard (including Bohlscheid \& Clark, 2012; Hollis \& Eren, 2016; Joyner, 2016; Morgan, Ismail, \& Hayes, 2006). 'Careers in Food Science: From Undergraduate to Professional', published in 2008 (Hartel \& Klawitter) targets US undergraduate students (or aspiring students) and includes examples of different career pathways in small chapters provided by representatives from US industry. Whilst perhaps inspirational in style to a student audience, it does not provide a clear scaffold of desirable competencies for each role to inform students and steer curriculum designers.

European work coordinated by the ISEKI Food Association (https://www.iseki-food.net) since 2010, has identified a selection of technical and "soft" skills that may be required in food scientists and technologists at varying levels of qualification on entry to industry (Flynn, Bejarano, Wahnstrom, Echim, \& Quintas, 2013; Ho, Lindbom, \& Wahnström, 2011; Mayor et al., 2015). However, there is no defined tool, model or guideline available from this work outlining the broader skills that make a workplace-ready food sciences graduate. UK-based careers information is limited; for example, 'Tasty Careers', (https://tastycareers.org.uk) is not graduate or technical specific, nor grounded in formal research. The overarching aim of the project was to construct a 'competency framework' outlining desirable qualities for typical roles undertaken by food science graduates in the UK and ROI food industry to support student 'employability' and engender clarity in graduate career opportunities for wider stakeholders. The framework can also underpin targeted curriculum development. To underpin the study, involvement of industry was critical. In previous work by the authors, a common language or tool was developed, using an exploratory process of 'semi-structured' or 'focused' interviews, thematic analysis and consolidation by an online modified Delphi group engagement activity (Weston, Crilly, Mossop, \& Foster, 2017). Competencies for Food Graduate Careers (CFGC) comprises 48 elements (and the associated definitions applied to them) that may be desirable in a UK food science graduate, subsequently checked for comprehension by a series of group interviews with students at three UK Universities.

The purpose of this study was to discover which elements in the CFGC language tool are particularly desirable for initial bachelors' graduate roles typically undertaken by food scientists in the UK and ROI. This paper commences by outlining the definition of these graduate roles in collaboration with a stakeholder group. The development, dissemination and analysis of a wider industry survey is described, aiming to establish the importance of each CFGC element for each graduate role. The present and future use of the finally ratified framework will be discussed.

\section{Materials and Methods}

The scope of this study does not center on the technical aspects of UK and ROI food science degrees as outlined in the QAA subject benchmark statement (2016), but on the broader behaviors, knowledge and skills that support a graduate's scientific knowledge and capability.

Stakeholders and Participants

In order to deliver a valid tool, a systematic approach utilizing a range of industry stakeholders was utilized. This included voices and views from human resource personnel, recruitment consultants, line managers/employers and recent graduates within the range of employment areas identified, such as manufacturing and retail. Sampling of these participants was purposive and through a process of snowballing via prior contacts (Braun \& Clarke, 2013). Aiming to gather an industry-wide perspective, extensive efforts were made to gather representation from range of initial graduate pathways, mindful that as 
some roles type are less frequently recruited to, associated participant numbers may be limited. A preferred mode of contact of direct email or using 'Linkedln' (Microsoft Corporation, California, USA) was established.

The survey was approved by the School of Sociology and Social Policy as aligned to University of Nottingham (UoN) Code of Research Conduct and Research Ethics. Informed consent was obtained from participants before survey completion.

Design

Using the language tool previously developed (Weston et al., 2017) to frame a stakeholder survey (Flynn, Bejarano, et al., 2013; Su \& Zhang, 2015), an exploratory sequential mixed methods approach to competency framework development was taken (Creswell, 2014). The process employed for this study is illustrated in Figure 1.

Preparatory work was progressed in 2016 and the survey was conducted in January 2017 . Choice of data analysis reflected the nature of data gathered and development of a useful final construct (Su \& Zhang, 2015; Velasco, 2012). The proposed framework was ratified by the industry stakeholder group in September 2017 as an expert forum (Joyner \& Stevenson, 2017; Perera, Babatunde, Zhou, Pearson, \& Ekundayo, 2016; Weston et al., 2017). There are an assortment of terms and associated definitions used in graduate competency constructs (Suleman, 2018), so careful application of terminology was required. Table 1 outlines the key terms and definitions used in the study.

\section{Establishing graduate roles}

A draft list was compiled of typical roles and associated titles that food science graduates may undertake as they enter the food industry, to instigate discussion in a stakeholder group meeting (comprising 11 attendees) in July 2016. This discussion confirmed that whilst some roles listed were less frequently advertised or recruited to, the range of identified career pathway options should be included in the study. A further desktop review was then undertaken of relevant careers guidance, job advertisements, and specifications found on UK websites and recent employment destinations of UoN food sciences alumni. A proposed list of 14 roles with associated titles and descriptors was electronically issued to the stakeholder group for consideration. Small revisions were made and a final list confirmed for the development of the survey.

Survey development

An anonymous online survey developed using Online Surveys ${ }^{\mathrm{TM}}$ (Jisc, Bristol, UK) was considered appropriate for the large sample size and geographical spread of target participants. Communications to accompany the single URL (uniform resource locator) weblink included carefully constructed introductory messages, adapted to the participant's prior knowledge of the study (Lawless \& Heymann, 1999). A draft survey was piloted with a small test group of eight and minor modifications were required to some wording of questions. The survey was launched in mid-January 2017.

The survey was constructed around the research question of 'What competencies are desirable in food sciences students for the initial roles they undertake after graduation?'

The survey presented the 48 elements of CFGC which participants had to rate according to their perception of the desirability of this component in the workplace for a given graduate role. The rating scale required a 'forced choice' owing to the expertise of the respondents (Brace, 2013). Participants could respond about as many roles as they were familiar with.

To aid completion, the 48 elements were listed within 11 zones, namely the original grouping of the elements (Weston et al., 2017) and appropriately sized subpages constructed. As illustrated in Figure 2, definitions were provided for each element within the question, and further explanatory text was provided at regular intervals by use of the 'more info' collapsible text box option, to guide and inform closed responses. To terminate each subpage, questions with free text or open responses were included, to allow the participant to provide optional qualitative information.

Core questions were structured in a five-point, ascending, unipolar Likert style scale with resultant useable scoring in the survey of ' 1 - not specifically desirable for the role' to ' 5 - essential for the role', as illustrated in Figure 2.

A series of initial, short anonymous demographic questions to facilitate data sorting, were included to establish the participant's relationship to graduates, whether: a 'recruiter', 'recent graduate', or an 'employer / line manager'. The use of the survey 'routing' feature prevented unnecessary additional questions being presented to a participant and use of the 'piping' feature allowed for their choice of role title to be cascaded into subsequent text and pages (Figure 2). A progress bar was omitted appreciating the encouraging benefit was more suited to short surveys (Brace, 2013), however radio buttons were employed to reduce the number of clicks for the user. 
As data was obtained from a sample of employers, inferential statistics were applied (Sapsford \& Jupp, 2006). Analysis was performed using non-parametric statistical methods, as appropriate for ordinal data from Likert style rating (Cohen, Manion, \& Morrison, 2011; Dillman, Smyth, \& Christian, 2014). Data were downloaded into Excel for analysis and an initial cleaning and inspection removed any errors/incomplete data.

A Chi-square test was undertaken to look for associations between variables (Sapsford \& Jupp, 2006) and support further investigation by multivariate analysis. The Cronbach's alpha reliability test was also conducted, using 0.6 as an acceptable lower limit for exploratory research (Hair, Black, Babin, \& Anderson, 2014). Two approaches of data analysis were applied and combined to generate the final framework of CFGC to present to stakeholders, comprising descriptive data analysis followed by principal component analysis (PCA).

Detailed descriptive analysis

This provided an opportunity to visualize data and establish relationships between variables. Desirability of each of the 48 specific elements of CFGC against the 14 typical graduate roles was explored by sorting data either by role or by element and inspecting data presented graphically in the following ways

- Stacked bar chart of responses, presented in descending order by role or by element.

- Frequency counts of the more desirable responses of ' 5 ' and ' $4 \& 5$ ' for an element by role type, presented in lists of descending order.

- The combined 'score' for each element by role type, converted and standardised to a common sample size for comparison purposes, using a 'score' for the total survey data set.

Roles or elements identified as 'top' in the visual inspection for each graph or list were captured and compared. Care was taken in interpreting roles with lower sample sizes ( $<10$ survey responses). A final list of desirable elements by role were compiled and a matrix generated for use in future illustrations. Principal component analysis (PCA)

PCA, a form of factor analysis, identifies patterns of correlations amongst the original variables and resolves them into a set of sensible groupings ('components') which each have a meaningful interpretation and a basis for the desired competency framework (Lawless \& Heymann, 1999). The process of identifying and choosing the best solution is not necessarily straightforward but PCA, in combination with careful inspection and comparison of the face validity of alternative solutions, offers a pragmatic and objective way forward.

Following initial pre-testing, based on a chosen number of retained components from the PCA, the configuration can be rotated so that, whilst retaining the same overall percentage of information from the complete data set, the original components are replaced by new ones each with an easier interpretation, namely components with higher positive or negative loadings on a reduced number of variables. The commonly-used Varimax procedure was used throughout in this study (Hair et al., 2014).

The alternative solutions with varying numbers of rotated components were then analyzed to select the best visualization of data. This included analysis for how many variables could be retained within each component (factor loading cut-off) assigning some meaning or identity to the construct and each component (Stevens, 2009). The terms 'factors' and 'components' are used interchangeably, also 'variables' and elements are equivalent in this study. PCA was performed on standardized data using XLSTAT TM Statistical Software (Addinsoft, NY, USA). Samples (participants) were entered in rows, and 'variables' (scored elements) in columns, plus 'supplementary variables' comprising codes for each participant, the participant type and typical graduate role chosen to review

Initial reliability of data were explored using the tables presented in the XLSTAT ${ }^{\mathrm{TM}}$ report. Bartlett's test of sphericity checks for correlations, having more limited value with a large data set and number of variables but was included in initial analysis (Field, 2013; Tabachnick \& Fidell, 2013)

A review of factor eigenvalues greater than 1.0, and inspection of cumulative variance supported choice of the range of components to inspect following rotations (Hair et al., 2014; Stevens, 2009). Cumulative variance, although typically required to meet thresholds such as $60 \%$, can be acceptable when lower in exploratory studies (Tabachnick \& Fidell, 2013). PCA software biplots, had limited use in the study due to a likely spread of useable components beyond two.

A summary of chosen criteria to support interpretation of rotational models is summarized in Table 2. Interpretation of each alternative rotated solution was approached in a sequential manner adapted from the steps described by Hair et al. (2014), enabliing choice of a final dimensional model and its most appropriate structure:

- Initial examination of each alternative rotated solution

- Factor communalities assessment 
- Identification of significant loading(s) for each factor

- $\quad$ Reflection on models and provisional labelling of factors

- $\quad$ Factor scores analysis

- $\quad$ Choice of the final rotational model

- $\quad$ Refinement of factor scores and model construct

After the structure was finalized, material was prepared to illustrate the CFGC framework and also a profile for each graduate role identified. The stakeholder group meeting (comprising 12 attendees) in September 2017 ratified the final construct (Perera et al., 2016) and possible visual representations of all aspects of the final framework were agreed.

\section{Results}

Figure 3 Illustrates the 14 roles identified as typical for food sciences graduates to initially undertake when entering the UK and ROI food industry. In total, the survey was sent directly to 250 individuals, and 218 fully completed responses were collected. Some responses included reviews of multiple roles. Following detailed inspection of data quality, the final data set comprised 226 reviews of the range of graduate roles. Focusing on the core questions, there appears general alignment between responses by types of participants (Table 3).

When sorted by responses to 14 typical graduate roles (Table 4) the data sets range from 3 to 55 participants. Appraising the lower sample sets (those with $<10$ responses), results generally appear to mirror the prevalence of the number roles usually on offer in the UK and ROI. This is based largely on personal knowledge of industry employment patterns and also the review of graduate role advertisements within this study, where for example the 'NPD, Development and Process roles' are one of the most common initial graduate positions to undertake. However, it is appreciated the six roles with lower sample sets (shaded in grey in illustrations) have limitations for robust statistical analysis. All data were retained reflecting stakeholder viewpoints that a full representation of the job market be included. Grouping smaller data sets would not be possible by any natural affiliation to provide meaningful outcomes, however care and sense was applied to analysis of these data sets and any judgments or comparison with other roles to prevent creation of bias.

Comparing the medians, there was little to differentiate between elements in the total data set, however visual inspection in graphical format provided some initial observations, for example the spread of results for the element, acceptance of ambiguity (Figure 4a) indicated relatively high desirability in the 'PhD or Other Postgraduate Research' role (Figure 4b).

Cronbach's alpha reliability test results provided scores of $>0.8$ with the exception of the role, 'Research or Materials Technologist', at 0.59 (a lower sample set role). However with closeness of the recommended threshold of 0.6 for exploratory research (Hair et al., 2014), all results were accepted. Chi-square test results confirmed that some correlations are significantly different, and thus the null hypothesis was be rejected and testing progressed.

\section{Detailed descriptive analysis}

Figure 5 provides an example of data presentation by a single element. In general elements scored more highly were positioned at the top or left area of the 48 elements for each representation. Decisions were supported by use of printed copies, to compare results effectively.

Table 5 provides a matrix summary of the descriptive analysis, illustrating between 10 to 14 elements with high desirability to each specific graduate role. Principal component analysis Bartlett's test of sphericity results confirmed suitability for progression. Retaining factors with eigenvalues $>1$, up to 12 factors were considered for future analysis with a total cumulative variance of $61.4 \%$. Observing the contribution of variability of each eigenvalue, PCA analyses were run to create four separate solutions by comprising six, seven, eight and nine dimensions and varimax rotations. After full analysis of these four dimensions based on the steps presented earlier, the eight varimax solution was determined to present the data most appropriately; the rationale is now summarized.

The variance data each rotational set in ascending order produced cumulative variances of: $45 \%, 48 \%, 51 \%$ and $54 \%$ respectively. Analysis of the factor matrix of four rotational sets commenced as described previously with the associated threshold and cut-offs summarized in Table 2 . Initial inspection of the content (elements) of components within each set were inspected allowing for practical reflection of each model with regard to the study context. For the nine rotational solution, the groupings did not appear rational or simple in terms of where the elements were found, which reflected in the sensibility of a final model, so this option was discarded.

Communalities were assessed for the remaining three rotational sets with a nominal threshold of 0.4 . For the eight rotational set average communality was 0.51. Three variables (elements) had communalities of $<0.4$ : acceptance of ambiguity (0.37), personable (0.36) and self-development (0.38). Reflecting on literature guidance, a decision was made to include all variables. For sets with six and seven dimensions, average communalities were lower at 0.45 and 0.48 respectively, with a greater number of individual communalities at $<0.4$, at 12 and 7 , respectively. 
With data sorted in each component by descending order of variables' (element), factor loadings for each rotational set were compared using initial factor loading cut-offs of 0.32 and 0.35 , to view which elements remained in each component. Using both cut-offs the work experience element was excluded the six rotational set, having a maximum factor loading of 0.207 . Aligned to stakeholder agreement that all 48 elements should remain, this set was therefore rejected. Using a 0.35 factor loading cut-off, all elements were included for eight rotations, but for seven rotations, two variables were excluded; namely selfdevelopment (D6, 0.337) and questioning approach (D6, 0.328). However using a 0.32 factor loading cut-off for both dimensional models, all elements were included. Further work proceeded with the seven and eight dimensional models.

Reviewing cross-loadings (an element found in two components) with a factor loading cut-off of $0.35,9$ cross-loadings were found with the seven dimensional model, and 12 cross-loadings for the eight dimensional equivalent (presented later in Figure 8 ). Using a 0.32 cut-off, the number of cross-loadings increased further (total of 17 for seven, 15 for eight rotated solutions). On this basis, factor loading cut-off was most appropriate at 0.35 . Reviewing each cross-loaded element against their provisional component labels, their double inclusion appeared justified. As such each element remained cross-loaded with affiliation to two components. With varimax rotation, the components are independent, so any future framework illustrations for CFGC should not demonstrably associate components or themes where an element is cross-loaded.

Draft names and definitions for each of the components in the two remaining rotated solutions were assigned, for stakeholder group agreement. Following the project stakeholder meeting in September 2017, components or 'groups' became known as themes, so terminology henceforth reflects this and the resulting model with eight themes and draft titles is illustrated later in Figure 8.

Factor score data for each rotated solution provided in the PCA test reports were grouped by role type, and the mean scores calculated for each theme. Initial cut-off points were applied, whereby factor scores of $\geq 0.40$ or $\leq-0.40$ were considered significantly positive or negative. This provided for each dimensional model, initial indication of relative affinity of a theme to each role assisting the final choice of construct.

PCA reduces variables to provide meaningful groupings, chosen by balancing empirical criteria with theoretical basis (Hair et al., 2014), so a judgement of the 'meaning' of each model was made. Preserving a discrete component relating to business aspects was concluded as useful when characterizing graduate roles, along with the inclusion of all elements in the final framework, so the final model of eight dimensions was chosen with an associated factor loading threshold of 0.35 . Although a small proportion of cross-loading and lower communalities were detected, contextual understanding of the subject under scrutiny can be included in exploratory research interpretation and the framework was meaningful for the study context.

Data for the final model was transposed and split into the 14 role types with further refined factor score thresholds, providing details of the relative desirability of a particular theme for a particular role (example in Figure 6). Identification of levels of desirability by (blue color) shading provides the ability for simple visual, interpretation mechanism.

\section{Culmination of survey data analysis}

After completion of data analysis, information was assembled for each of the 14 role types with regard to desirable elements (descriptive analysis) and also relative affinity to the new eight themes (PCA). A report was developed in advance for review and approval in a roundtable session with the stakeholder group and representation from IFST.

The draft names and definitions for the eight themes derived from PCA were presented and reviewed to ensure appropriate definitions were developed with the student as target audience. The final construct is presented in Table 6.

From the stakeholders' experience, the resulting desirability of themes to each role appeared appropriate. For example, a 'PhD' pathway may require a particularly high level of some specific competencies, whereas for a 'Company Graduate Scheme', employers may require graduates to possess a more balanced set of competencies. A new pictorial illustration was proposed and approved, indicating relative importance of a theme by the darkness of blue shading (Figure 7).

Thus, a new grouping of eight themes to replace the original 11 zones (Weston et al., 2017) was ratified by the project stakeholder group. Consideration was made to appropriate treatment and display of the 12 cross-loaded elements using the diagram provided (Figure 8). The prevailing view was to provide simplicity and ease of understanding of CFGC to priority audiences, namely undergraduate students and employers.

A new pinwheel design was constructed (Figure 9) to illustrate the eight themes. In summary CFGC, now comprised:

- A language tool of 48 elements grouped into eight themes.

- 14 typical graduate roles for food scientists.

- An industry informed framework of the desirable elements and themes for each of the 14 roles. 


\section{Discussion}

CFGC is aimed to ensure program provision by educators meets the professional requirements of employers and in turn, students are able to understand more about job opportunities, their suitability and how to prepare for application and selection processes. These aims will be discussed later. However it is interesting to review the variation in element's frequency of inclusion (Table 5) where questioning approach and verbal communication are considered desirable in half of the 14 roles, and three elements, digital capability, global supply chain and work experience are only included once. It could be suggested that some elements with lower occurrences may increase in desirability for the workplace in future. As noted earlier, Figure 7 highlights the differences in relative desirability of themes to roles, such as where $D 7$ - dependability and experience is highly prized for laboratory-based or regulatory roles. Overall the role profiles generated (see Supporting Information as an example) are judged suitable as targeted descriptors for these graduate roles.

\section{Review of methodology}

The use of the ordinal survey scale was most applicable for the intended use, but limited data handling options. As target survey participants were 'untrained participants' remotely spread across the UK and ROI, assurance was not possible that defined equidistant scale intervals would be used correctly. The inclusion of more points on the scale e.g. seven, may have created more differentiation, but also participant burden (Dillman et al., 2014) and clutter on a text labelled scale.

Suleman's (2018) recent comparison of past approaches to building competency frameworks suggests caution in providing a predefined list of skills to employers or graduates; however this study utilized the viewpoints of employers themselves to build the lexicon and associated definitions (Weston et al., 2017), also suggested by Suleman. This is hoped to provide the required validity.

The relatively low sample size $(<10)$ for six of the typical graduate roles (sizes ranging from three to eight) is a limitation, however fewer survey participants were captured for roles less commonly recruited to. As all data was retained, analysis and interpretation was undertaken with careful consideration, and roles with low sample sizes identified in all outputs and published material to highlight possible limitations.

Selected approaches to data analysis have developed discrete role profiles and an exploratory PCA of survey data has enabled the generation of meaningful themes from the CFGC language tool. Splitting the original data set, and retesting did not indicate the final framework has significant generalizability (Field, 2013; Hair et al., 2014). The study and criteria applied is suggested to be treated as a discrete experiment, and studies with alternative context, such as another employment sector should be approached as new. However if the same survey was undertaken with the same population type of UK and ROI food industry employers, there is a likelihood for repeatability. CFGC is a credible indicator to students and HEls of which desirable themes are aligned to different food science graduate roles. Exploration of responses during PCA has not indicated grouping of responses by the 14 subpages and thus influence on theme construction, for example, theme D2 - appreciation of the wider world contains elements from two different subpages.

As for studies of this nature, CFGC captures a time-framed view of UK and ROI recruitment in 2017 and will not account for any significant future change. However with no equivalent research-based framework of any age in the UK and ROI it is reasoned that having a tailored framework in place for food sciences students to utilize, is more beneficial than none.

\section{Current use of CFGC framework}

Opportunities for use of CFGC following the study have been discussed with the stakeholder group and sessions with students and other wider industry audiences. Material created from the study was compiled into role profiles, highlighting the key desirable elements and themes in a simple 'infographic' poster. The widely recruited 'NPD, Development or Process' role as an example, is found in Supporting Information. In collaboration with the stakeholder group, a report was created and published in October 2017 on the IFST website (Weston, 2018). Freely accessible to other degree educators, students and employers, it includes an outline of the framework and access to all 14 infographic posters. A simple interactive open access online tool, has also been created (University of Nottingham, n.d.) aiming to provide careers guidance for students and new graduates and support personal development and job application preparation.

CFGC has direct use in undergraduate career education and personal development. Feedback from surveys and group interviews, following integration into student teaching at UoN has been encouraging. By accessing open access CFGC resources, other UK higher education institutes (HEIs) have introduced the framework to support careers education and research.

\section{Comparison of data to previous studies}

Using the frequency of inclusion of a CFGC element into one of the 14 typical graduate roles (see Table 5) those with a higher count and thus most likely to be desirable are illustrated in Table 7. For general employability frameworks some 'skills' appear in most studies and include technical (IT), analytical, communication and teamworking as well as 'personal traits' (Suleman, 2018). These all (aside from the IT skills) appear to correlate well with Table 7. 
There is limited cohesive previous work to define and describe typical roles for food sciences graduates. Hartel and Klawitter's book (2008) does provide variable levels of detail on required competencies for some USA-based graduate roles. The 10 pathways (chapters) authored by specialists from the field are largely similar to the 14 typical roles established in this project, which is encouraging. However the CFGC framework is built on extensive industry research and material produced allows for ease of review or comparison of all graduate roles for food scientists. With respect to generic graduate requirements, at the time of the study, the IFT standard (2016) in the USA had a 'success skills' domain, less technical in focus, appearing to include five CFGC elements. However a newly published IFT requirements (2019) includes 11 standards of which four encompass at least 13 CFGC elements, including explicitly written and verbal communication, leadership, critical thinking and independence. One US institute (Morgan et al., 2006) engaged their Industry Advisory Board in a survey, to establish relative importance of constituents in the entire IFT standard. Whilst acknowledging the restricted number of participants, results demonstrate 11 of the 13 'outcomes' of the success skills group in the standard are rated relatively highly. No previous work has been undertaken in the UK or ROI to explore specific detail for food science degrees. The labels of the seven sections of 'generic skills' in the UK's QAA benchmark standard (2016) for Agriculture, Horticulture, Forestry, Food, Nutrition and Consumer Sciences are not opposed to the elements in CFGC but are essentially a general list. For both UK (QAA) and USA (IFT) contexts it is unlikely anyone would question the advantage of possession of the 'skills' listed in both documents, but no research-based detail has been given with weighting of these specific competencies required against different food science graduate roles.

The list of 'soft skills' for food scientists and technologists generated by ISEKI within Europe (including the UK) has no specific profiles for graduates (Flynn, Wahnström, Popa, Ruiz-Bejarano, \& Quintas, 2013; Mayor et al., 2015). Flynn et al's. study established 'communicating' as the number one sector or nonsector (soft) skill which aligns well to high counts of verbal and written communication in CFGC (Table 7). Some regional variation was observed; with 'working with others' reaching the top three only in southern Europe (aligned to CFGC), whilst a technical skill, 'product development' is rated more highly in the north (Flynn et al., 2013b), however this possible variation has not been subsequently explored or verified.

\section{Recent and future work}

With regard to careers education, collaboration is planned from autumn 2019 with a selection of HEls exploring the use of CFGC. Food science educators Joyner and Stevenson (2017) observe the 'trend' is to teach to enable students to perform well in specific career pathways. The frequency of particular elements' appearance in the 14 role profiles (Table 5) is of interest, and may provide some context to relative priority for development of elements in student cohorts. Curriculum mapping of CFGC against UoN food science degree programs was conducted from 2017 to 2018 with subsequent reflection and program development; this will be presented in a future paper.

The encouraging level of industry engagement in the process reflects employers' interest in ensuring degree providers develop 'oven-ready' graduates. CFGC has been introduced to industry at a number of opportunities, to inform and test development of the framework. By employers using CFGC to improve the accuracy of recruitment and selection processes there could be significant value in securing the right candidate, so initial exploration in developing targeted content in job specifications and advertisements has commenced. Ideally the industry survey should be repeated a few years hence, using the same approach, to test repeatability and gauge if employers' have altered opinions of the desirable competencies for food science graduates (as suggested earlier).

It is suggested CFGC could support compliance in IFST degree accreditation (n.d.) for aspects such as employability, competency development and careers education. It is anticipated inclusion of CFGC into criteria will be approved in due course, resulting in consistency of competency development in UK degree courses beyond compliance to the technical aspects already outlined in the appropriate QAA benchmark statement (2016). Finally CFGC could support initiatives to inspire and inform pupils in compulsory education to choose food science based courses.

\section{Conclusion}

A framework, supported by an appropriate language tool was developed, to illustrate the relative importance of specific competencies to the types of jobs food sciences students typically undertake after graduation in the UK and ROI. In shaping a suitable survey and ensuring wide industry participation, a unique data set was acquired. Following suitable data analysis and stakeholder ratification, a framework of desirable competencies for 14 typical roles has been produced highlighting there is no general blueprint for an ideal food science graduate. In this region, CFGC fills a novel gap in knowledge, superseding only general profiles. CFGC has been disseminated in open access resources (ttp://bit.ly/foodgrad and http://www.nottingham.ac.uk/go/foodcareers) and provides an objective and useful reference for educators, students, graduates and employers.

\section{Acknowledgments}


The authors would like to express appreciation to the project stakeholder group for their valuable support and wider industry participants for their time in completing the survey. In addition, we sincerely thank Graham Cleaver for his advice on statistical analysis, and colleagues at University of Nottingham for their support in the study.

\section{Author Contributions (required for JFS original research manuscripts)}

Emma Weston was responsible for the design, implementation and data analysis for the project and drafted the manuscript. Liz Mossop contributed to the design of the survey and manuscript revision. Tim Foster and Jim Crilly engaged industry support for survey completion and contributed to the final construct of the framework, and Tim also the manuscript revision.

\section{Nomenclature or Appendix}

N/A.

\section{Supplemental Information - 1 of}

Title

Example graduate role infographic - NPD, Development or Process role

\section{References}

Bohlscheid, J., \& Clark, S. (2012). Career preparedness survey outcomes of food science graduates: a follow-up assessment. Journal of Food Science Education, 11(2), 8-15. doi:https://dx.doi.org/10.1111/j.1541-4329.2011.00139.x

Brace, I. (2013). Questionnaire design: how to plan, structure and write survey material for effective market research (3rd ed). London: Kogan Page.

Braun, V., \& Clarke, V. (2013). Successful qualitative research: a practical guide for beginners. London: Sage.

Cohen, L., Manion, L., \& Morrison, K. (2011). Research methods in education (7th ed). London: Routledge.

Creswell, J. W. (2014). Research design: qualitative, quantitative, and mixed method approaches (4th ed). London: Sage.

Dillman, D. A., Smyth, J. D., \& Christian, L. M. (2014). Internet, phone, mail, and mixed-mode surveys: the tailored design method (4th ed). Hoboken, New Jersey: Wiley.

Field, A. P. (2013). Discovering statistics using IBM SPSS statistics: and sex and drugs and rock ' $n$ ' roll (4th ed). London: Sage.

Flynn, K., Bejarano, B. R., Wahnstrom, E., Echim, C., \& Quintas, M. A. C. (2013). Profile of currently employed European food scientists and technologists: education, experience and skills. International Journal of Food Studies, 2(2), 137-149. doi:https://doi.org/10.7455/ijfs/2.2.2013.a1

Flynn, K., Wahnström, E., Popa, M., Ruiz-Bejarano, B., \& Quintas, M. A. C. (2013). Ideal skills for European food scientists and technologists: identifying the most desired knowledge, skills and competencies. Innovative Food Science and Emerging Technologies, 18, $246-255$. doi:https://doi.org/10.1016/j.ifset.2012.09.004

Hair, J. F., Black, W. C., Babin, B. J., \& Anderson, R. E. (2014). Multivariate data analysis (7th ed). Harlow, UK: Pearson.

Hartel, R. W., \& Klawitter, C. P. (2008). Careers in food science: from undergraduate to professional. New York: Springer.

Ho, P., Lindbom, I., \& Wahnström, E. (2011). Knowledge and skills requirements for careers in the food industry. Draft Version 2.0. Track_Fast. Unpublished.

Hollis, F. H., \& Eren, F. (2016). Implementation of real-world experiential learning in a food science course using a food industry-integrated approach. Journal of Food Science Education, 15(4), 109-119. doi:https://dx.doi.org/10.1111/1541-4329.12092

Institute of Food Science and Technology. (n.d.). Accreditation of degree courses. Retrieved from https://www.ifst.org/accreditation/accreditation-degreecourses. Accessed 20 April 2019.

Institute of Food Technologists. (2016). Education standards for approved undergraduate programs. Retrieved from http://www.ift.org/ /media/Knowledge\%20Center/Learn\%20Food\%20Science/Become\%20a\%20Food\%20Scientist/Resources/ResourceGuide_Unde rgradFoodScience.pdf

Institute of Food Technologists. (2019) 2018 Guidelines for Initial IFT Approval of Undergraduate Food Science and Food Technology Programs. Retrieved from https://www.ift.org/-/media/community/educators-

herb/2018herbguidelinesforinitialiftapproval.pdf?la=en\&hash=CE95A2112734A8DDCFBE0E04BAE72BDF338E9F09

Joyner, H. S. (2016). Curriculum mapping: a method to assess and refine undergraduate degree programs. Journal of Food Science Education, 15(3), 83100. doi:https://doi.org/10.1111/1541-4329.12086 
Joyner, H. S., \& Stevenson, C. D. (2017). If you don't know, ask! Using expert knowledge to determine what content is needed in an undergraduate food quality management and control course. Journal of Food Science Education, 16(1), 19-27. doi:https://doi.org/10.1111/1541-4329.12101

Lawless, H. T., \& Heymann, H. (1999). Sensory evaluation of food: principles and practices. New York \& London: Kluwer Academic/Plenum Publishers.

Mayor, L., Flynn, K., Dermesonluoglu, E., Pittia, P., Baderstedt, E., Ruiz-bejarano, B., . . Costa, R. (2015). Skill development in food professionals: a European study. European Food Research and Technology, 240(5), 871-884. doi:http://dx.doi.org/10.1007/s00217-014-2400-z

Morgan, M. T., Ismail, B., \& Hayes, K. (2006). Relative importance of the institute of food technologists (IFT) core competencies: a case study survey. Journal of Food Science Education, 5(2), 35-39. doi:https://doi.org/10.1111/j.1541-4329.2006.tb00080.x

Perera, S., Babatunde, S. O., Zhou, L., Pearson, J., \& Ekundayo, D. (2016). Competency mapping framework for regulating professionally oriented degree programmes in higher education. Studies in Higher Education, 42(12), 2316-2342. doi:https://doi.org/10.1080/03075079.2016.1143926

Sapsford, R., \& Jupp, V. (2006). Data collection and analysis (2nd ed). London: Sage

Schönemann, P. (1981). Power as a function of communality in factor analysis. Bulletin of the Psychonomic Society, 17(1), 57-60. doi:https://doi.org/10.3758/BF03333667

Stevens, J. (2009). Applied multivariate statistics for the social sciences (5th ed). New York \& Hove: Routledge.

Su, W., \& Zhang, M. (2015). An integrative model for measuring graduates' employability skills: a study in China. Cogent Business and Management, 2(1) doi:https://doi.org/10.1080/23311975.2015.1060729

Suleman, F. (2018). The employability skills of higher education graduates: insights into conceptual frameworks and methodological options. Higher Education, 76(2), 263-278. doi:https://doi.org/10.1007/s10734-017-0207-0

Tabachnick, B. G., \& Fidell, L. S. (2013). Using multivariate statistics (6th ed). Boston, Mass. \& London: Pearson.

The Quality Assurance Agency for Higher Education. (2016). QAA Subject benchmark statement: agriculture, horticulture, forestry, food, nutrition and consumer sciences. Retrieved from https://www.qaa.ac.uk/docs/qaa/subject-benchmark-statements/sbs-agriculture-horticulture-forestry-foodnutrition-consumer-sciences-16.pdf?sfvrsn=67f2f781_20

University of Nottingham. (n.d.). Welcome to the competencies for food graduate careers toolkit. Retrieved from http://www.nottingham.ac.uk/go/foodcareers

Velasco, M. S. (2012). More than just good grades: candidates' perceptions about the skills and attributes employers seek in new graduates. Journal of Business Economics and Management, 13(3), 499-517. doi:https://doi.org/10.3846/16111699.2011.620150

Westad, F., Hersleth, M., Lea, P., \& Martens, H. (2003). Variable selection in PCA in sensory descriptive and consumer data. Food Quality and Preference, 14(5-6), 463-472. doi:https://doi.org/10.1016/S0950-3293(03)00015-6

Weston, E. (2018). Competencies for Food Graduate Careers Retrieved from https://www.ifst.org/knowledge-centre-other-knowledge/competencies-foodgraduate-careers

Weston, E., Crilly, J., Mossop, L., \& Foster, T. (2017). Competencies for food graduate careers: developing a language tool. Higher Education Pedagogies, 2(1), 101-115. doi:https://doi.org/10.1080/23752696.2017.1366275

\section{LIST of CAPTIONS FOR TABLES AND FIGURES}

Tables All attached as excel files

Table 1 - Glossary of terms established for use in the competency framework developed during the study.

Table 2 - Summary of the chosen criteria for PCA initial data interpretation.

Table 3 - Analysis of survey by participant type, focusing on the rating questions ${ }^{\text {a }}$ presented, one for each element

Table 4 - Summary of survey responses by typical initial graduate role reviewed and participant type

Table 5- Matrix of desirable elements by typical graduate role presented in alphabetical order

Table 6 - Construct of eight themes of desirable competencies in CFGC

Table 7 - Frequency count of inclusion of desirability of an element into one of the 14 role profiles in CFGC.

Figures All attached as TIFF or pdf files

Figure 1 - Approach undertaken for the study.

Figure 2 - Reproduction of the modified unipolar Likert style questions and the use of piping to provide context to text by adding role chosen by participant, e.g. 'Factory Based Technologist'.

Figure 3 - Illustration of final 14 typical graduate roles for food science graduates. The roles on the right are classically situated within a point of the supply chain from concept to consumer, and those on the left are tend to be broader or overarching within the UK food industry. 
464 Figure 4 - An example of initial data inspection from the industry survey for the element acceptance of ambiguity, where (a) displays full data and (b) responses specific to the role 'PhD or Other Postgraduate Research'.

Figure 5 - Inspection of data by element with entrepreneurship as an example where (a) presented a stacked bar chart of response data and (b) a standardised total scoring for comparison to a 'mean' standardised score (red line).

Figure 6 - Development of PCA factor scores (eight varimax dimensional model) illustrating refined desirability of themes to the 'Specifications / Quality Systems Technologist' role. Draft labels for the themes are included.

471 Figure 7 - Illustration of relative importance of each theme in CFGC against each typical graduate role.

472 Figure 8 - New structure of CFGC presenting elements within each theme in order of factor loading (highest at top) and cross-loading of elements 473 highlighted with yellow shading. 